http://dx.doi.org/10.30681/23588403v12i017789

\title{
FISGANDO ILUSTRAÇÕES E POESIA EM POEMINHAS PESCADOS NUMA FALA DE JOÃO
}

\author{
Data de recebimento: 18/04/2019 \\ Aceite: 08/06/2019 \\ Dayane Cristine Santos VIEIRA (UFMT) ${ }^{1}$ \\ Célia Maria Domingues da Rocha REIS (UFMT) ${ }^{2}$
}

\begin{abstract}
Resumo: Neste trabalho desenvolvemos um exercício de análise de ilustrações em intersecção com poemas. Para o corpus, foram selecionados poemas de Manoel de Barros e ilustrações de Ana Raquel, ambos publicados na obra Poeminhas pescados numa fala de João (BARROS, 2001). Foram abordados elementos da linguagem pictórica, superfície, volume, luz, e cor (OSTROWER, 1996), e da poética, nos aspectos formais. Ainda quanto ao texto poético, baseamo-nos na teoria da matéria bachelardiana, para mostrar como se constroem as ideias oníricas de imaginação da água. As ilustrações aliadas aos versos, colaboram para o vínculo de unidade e ternura entre o menino e o rio.
\end{abstract}

Palavras-Chave: Poema. Ilustração. Manoel de Barros.

\begin{abstract}
In this paper we develop an exercise of analysis of illustrations in intersection with poems. To the corpus, poems of Manoel de Barros and illustrations of Ana Raquel were selected, both published in the work Poeminhas pescados numa fala de João (BARROS, 2001). Elements of pictorial language, surface, volume, light and color were approached (OSTROWER, 1996), and of the poetic, in the formal aspects. Still regarding to the poetic text, we based ourselves in the theory of the bachelardian matter, to show how are built the oneiric ideas of imagination of water. The illustrations allied to the verses collaborate to the bond of the unit and the tenderness between the boy and the river.
\end{abstract}

Keywords: Poems. Illustration. Manoel de Barros.

\section{Introdução}

Os Poeminhas pescados numa fala de João, do poeta Manoel de Barros foram originalmente publicados em Compêndio para uso dos pássaros, em 1961. Em 2001, a editora Record faz nova publicação, mas, a nosso ver, com projeto gráfico voltado ao público infantojuvenil, embora, o livro possa naturalmente, ser lidos pelos adultos. Nessa edição, inserem-se as imagens feitas por Ana Raquel - segundo ela, criadas “com alma emprestada de

\footnotetext{
${ }^{1}$ Mestre em Estudos de Linguagem (Área de Concentração: Estudos Literários) pela UFMT/Cuiabá/MT. Reside em Cuiabá/Brasil. E-mail: dayanecsvieira@hotmail.com

${ }^{2}$ Doutora em Literatura Brasileira pela UNESP/São José do Rio Preto/SP. Reside em Cuiabá/Brasil. E-mail: celiadr@uol.com.br
} 
passarim" (2001, n.p.). "Pescar poemas" é o mote do poeta e, consequentemente, da ilustradora.

A obra é composta por um grande poema, dividido em nove partes, os "poeminhas", que se relacionam uns com os outros. Desse conjunto recortamos quatro, voltados à temática das águas.

A obra, então, constitui-se como texto híbrido, no qual se relacio venam versos e ilustrações. Estas adquirem certa autonomia, não permitindo serem vistas como mero complemento dos poemas, hipótese que levaria "o leitor a buscar na ilustração apenas os significados do texto, o que empobrece a leitura, pois aquilo que a ilustração 'diz' e não está no texto não é percebido”, explica Luiz Camargo (2003, p.274).

Para analisar e interpretar as ilustrações, serão estudados os seus elementos componentes - superfície, volume, luz e, principalmente, a cor, de acordo com as teorias de Fayga Ostrower (1996) e Israel Pedrosa (2014). A água, principal temática do corpus, é aqui discutida como imaginação da matéria, de acordo com o viés bachelardiano (2013). Por meio desses estudos, observaremos o modo como se opera a linguagem, em suas funções, segundo Camargo as estabelece, com base em Jakobson (apud CAMARGO, 2003) como a lúdica, que ocorre quando a ilustração se configura como jogo em relação ao emissor, destinatário e forma da mensagem; e a expressiva, que enfatiza emoções e valores dos seres representados (CAMARGO, 2003).

\section{Bebendo na fonte do João}

Figura 1 - Ilustração de Ana Raquel para a capa do livro. 


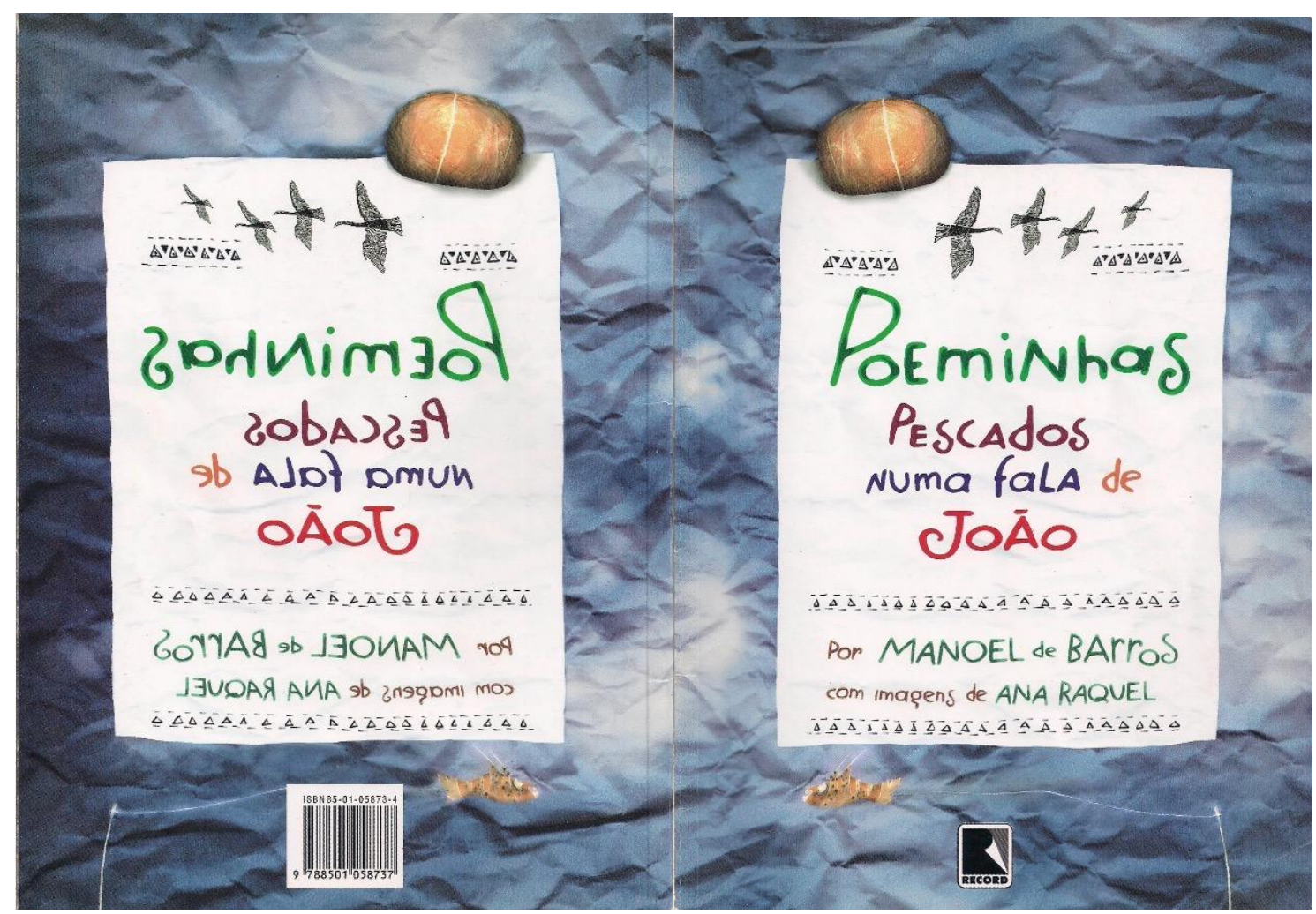

Fonte: BARROS, 2001, n.p.

O título do livro escrito num desenho de folha de papel está centralizado e posto sobre fundo azul, ocupando a maior parte do plano. O fundo branco do papel destaca a cromaticidade das cinco cores. Verde e vermelho, cores da primeira e última palavra do título, parecem aproximá-las por pertencerem ao mesmo grupo complementar (OSTROWER, 1996), destacando-se também pelo tamanho da fonte, maior que a das demais palavras. Interessante perceber ainda, numa ordem de baixo para cima, que o vermelho (“João") e o azul ("numa fala") misturados criam o violeta ("pescados"). Além do colorido, o diminutivo e a mistura de maiúsculas e minúsculas, lembrando a escrita de criança, garantem o efeito lúdico.

O laranja, cor quente, preenche estrategicamente uma pequena parte do título no centro vertical e levemente pendido para a direita, no sentido horizontal; a pedra, no canto superior esquerdo; e o peixe, no periférico inferior, sugerindo a imagem virtual de um triângulo pendido para a direita, na mesma direção em que voam os pássaros desenhados entre a pedra e o título, induzindo o leitor a abrir o livro.

Na figura do peixe, o que se destaca é a luminosidade, que resulta do contraste de tons claros e escuros, dando movimento visual, pois, para Ostrower, "não basta haver uma área clara se destacando de outras escuras [...]. Para que o elemento se torne expressivo, é preciso todo o movimento visual desdobrar-se através de valores claros e escuros" (OSTROWER, 1996, p.223). Quanto à figura da pedra, o elemento formal é a superfície, e 
não a luz. Com dimensões de altura e largura bem definidas, é bidimensional; embora sejam visíveis tons claros e escuros, não apresenta movimento. A pedra está imóvel no seu ofício de peso para papel.

O papel branco que, como dito, ocupa grande parte da capa, parece flutuar sobre o azul - as águas, e os pontos de luminosidade permitem que vejamos sua claridade. A capa da frente é especular em relação à de trás. Este conjunto de procedimentos artísticos, permeados pelas águas, na expressão do imaginário de "João", podem ser fundamentados no que diz Bachelard sobre o fato de não se sonhar "profundamente com objetos", mas "com matérias. Um poeta que começa pelo espelho deve chegar à água da fonte se quiser transmitir sua experiência poética completa" (2013, p.24).

No próprio título já percebemos, pelo jogo de palavras, a relação entre a poesia e a água (matéria da natureza). A ideia do pescar, de imediato, faz-nos mirar um rio, lagoa, mar... aproximarmo-nos de suas margens, antecipando o que pode brotar dali. O projeto gráfico torna-se criativo e estimulante se associarmos a capa à ideia do porvir.

$\mathrm{Na}$ ilustração do poema I predominam os tons terrosos quentes resultantes do amarelo, vermelho e preto (PEDROSA, 2014), criando o marrom avermelhado que se observa nas folhas e na água próxima ao poema. As bordas cor "terra-de-siena” garantem o equilíbrio.

Figura 2 - Ilustração de Ana Raquel para o poema I. 


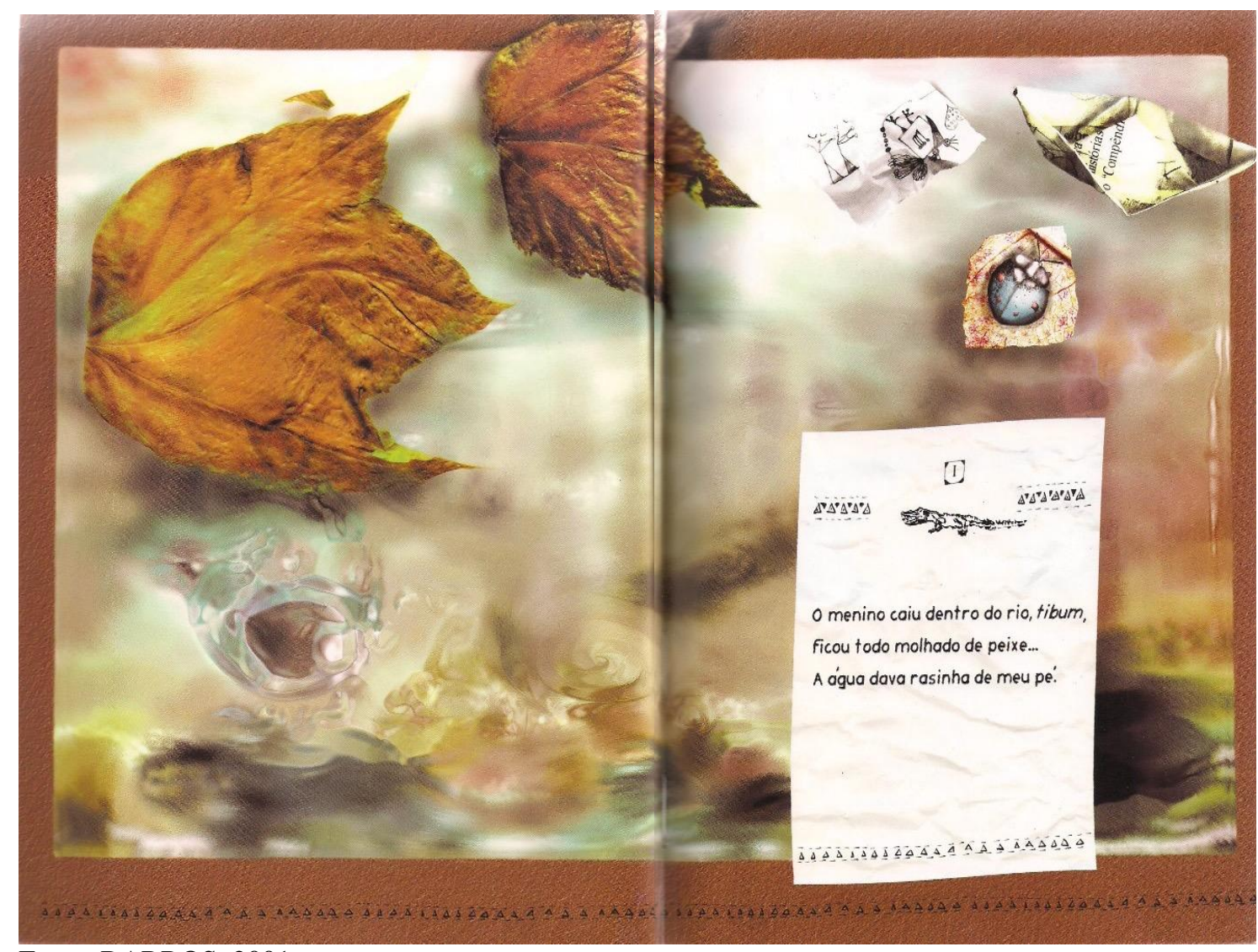

Fonte: BARROS, 2001, n.p.

Observamos com nitidez as folhas de árvores. Nas águas claras, frescas, as sombras se misturam colorindo o rio com pinceladas de tinta, o que lhes dá o movimento de uma leve correnteza. "A água é, sob certos aspectos, o frescor substantivado. Marca um clima poético" (BACHELARD, 2013, p.34, grifos do autor).

Verificam-se ainda, no retângulo branco - suporte para o poema, que pode ser visto como uma folha de papel -, pequenos desenhos feitos com tinta preta, na parte superior, sempre com motivos aquáticos. Essa característica é recorrente em todos os "poeminhas" do livro. Nesse primeiro, a figura do jacaré, que é citado apenas no sexto verso do poema II.

Ainda sobre o poema I, temos a imagem interna do rio ( nos versos 1 e 2) onde o menino cai - o eu lírico apresenta o fato em $3^{\mathrm{a}}$ pessoa; e externa (verso 3), por meio de discurso direto, em que se constata sua profundidade pela altura com que a água cobre o pé da criança,.

I

O menino caiu dentro do rio, tibum,

Ficou todo molhado de peixe...

A água dava rasinha de meu pé.

(BARROS, 2001, n.p.) 
De tão rasa, visualizamos um peixe se movendo assustado (abaixo da grande folha de tom terroso) com a entrada de algo, perceptível por tons sombreados nas águas. Seria o João?. O contorno azul acinzentado reforça a claridade da água. No centro inferior, os movimentos circulares se relacionam com a onomatopeia "tibum": o local e o som provocados pela queda no rio.

Uma característica na formatação do livro é o uso da fonte Comic Sans MS, na escrita dos "poeminhas". Esta fonte atenua a formalidade ao mesmo tempo em que traz o tom de divertimento e leveza para o texto.

O eu lírico João diz o que vê e sente, com naturalidade, e nisso reside o estado de poesia que envolve o conteúdo da fala. Nessa imagem poética, a criança toma um componente do rio, o "peixe", pela propriedade da água, a de umedecer as substâncias, o que provoca efeito de comicidade: ficar "molhado de peixe", uma sinédoque. No terceiro verso, a preposição "de" no lugar de "no" garante o efeito poético. Como disse o poeta, no documentário Só dez por cento é mentira (2008): "Erra na gramática e acerta na poesia”. Para Bastos, "as palavras recebem torpezas, demências, vaidades em sua depuração para a poesia [...]. E se mostram despidas das impurezas como Manoel as desejou, para a nós se expor e emocionar" (2004, p.91).

Na mesma direção, está o poema II:

Figura 3 - Ilustração de Ana Raquel para o poema II. 


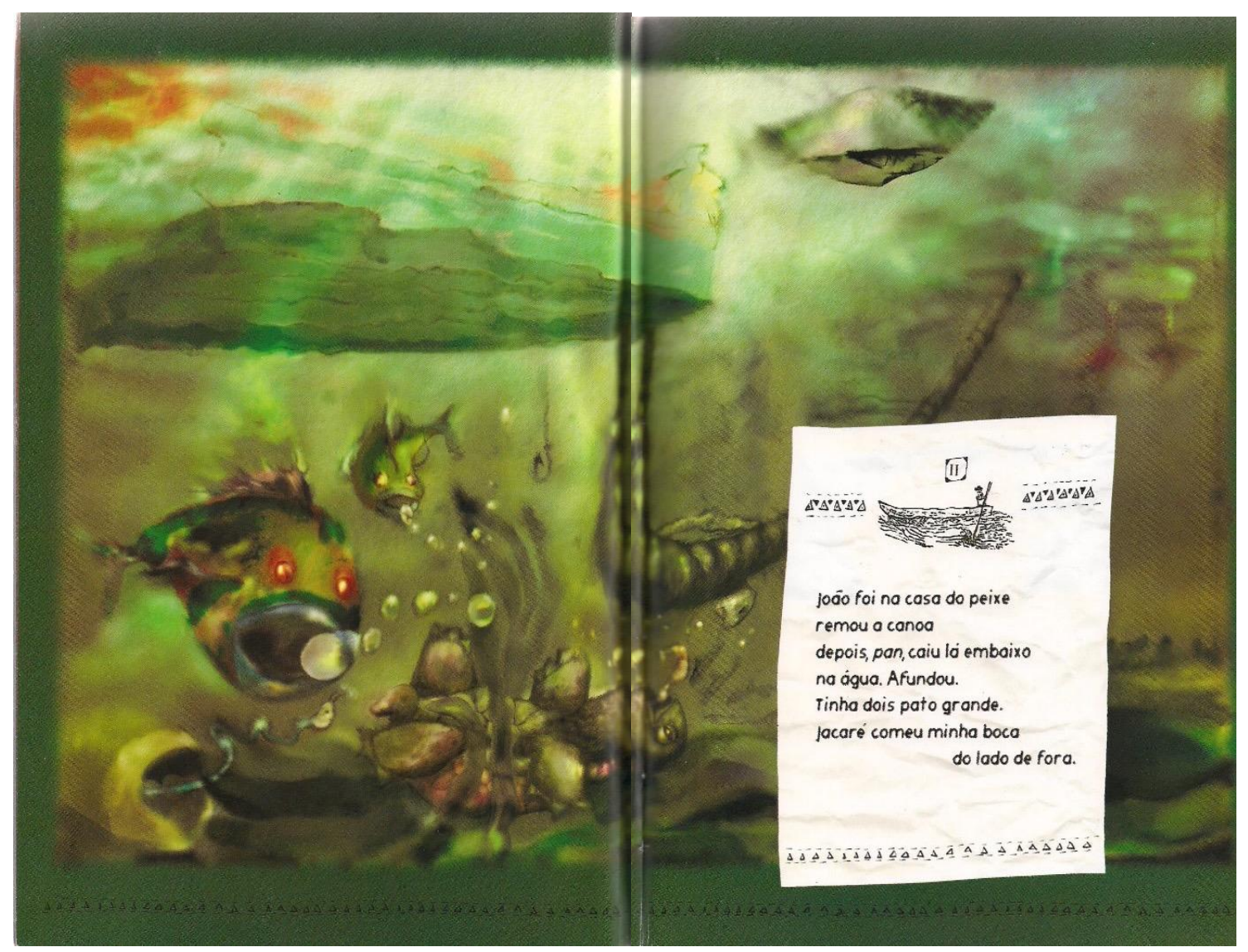

Fonte: BARROS, 2001, n.p.

A ilustração mostra o acontecimento posterior à do poema I, em dupla perspectiva: colorida, debaixo d'água; na superfície do papel onde está escrito o poema, com traços pretos compondo um homem em uma canoa, remando.

Debaixo d'água podemos ver o tom alaranjado das folhas e o fundo do barquinho de papel. Ambos flutuavam na superfície da água na ilustração anterior. Uns feixes verticais de luz clareiam a imagem, possibilitando a identificação do barquinho. Na parte superior à esquerda, o verde escuro cobre uma extensão horizontal, que tem o formato de uma canoa, muito provavelmente, a do João:

II

João foi na casa do peixe remou a canoa

depois, pan, caiu lá embaixo na água. Afundou.

Tinha dois pato grande.

Jacaré comeu minha boca

(BARROS, 2001, n.p.) do lado de fora. 
Além desses, há outros elementos que compõem o cenário do fundo do rio, num diálogo metafórico com o poema. De pernas para cima vê-se uma tartaruga, representando o João, que é quem cai "lá embaixo / na água; um pato, um pouco abaixo e à esquerda do barquinho de papel, que poderia passar despercebido não fosse a leitura do quinto verso: “Tinha dois pato grande." Percebe-se a divergência entre as quantidades no poema e na ilustração.Para esta, corresponderia ao substantivo no singular, e pode ser mesmo este o motivo da representação de apenas um pato. Quanto à inadequação gramatical, GráciaRodrigues e Moraes (2015, p.318) explicam que, “o próprio numeral 'dois' se encarrega de dar ao leitor a noção semântica de que se trata de mais de um pato, sendo desnecessária a flexão do substantivo".

Os versos 6 e 7 apresentam uma ação incongruente, a do sáurio comer a boca. Interessante perceber a associação gráfico-semântica do último verso: escrito a partir do meio da linha, supera os demais versos em extensão, ficando, então "do lado de fora". Um verso sobreposto ao outro provocam um desenho alongado, pictoricamente sugerindo a boca do jacaré.

Outros animais aparecem na ilustração - duas cobras e dois peixes. O peixe maior ganha destaque: com olhos vermelhos sobre a cor verde, torna-se a mais vibrante das combinações complementares. "Aplicado em pequenas porções sobre o fundo verde, agita-se e causa desagradável sensação de crepitação" (PEDROSA, 2014, p.119). A planejada combinação das cores que produzem o efeito esbraseado dos olhos, a grande boca aberta e as bolhas destacam a função expressiva da linguagem plástica.

Embora o tom esverdeado das águas cause um escurecimento, é certo dizer da claridade que possibilita sua contemplação. Especialmente nesta, em que visualizamos o que acontece "na casa do peixe", as figuras aparecem um tanto borradas, expressando movimentos mais lentos dentro d'água, o que direciona o leitor à linguagem dos sonhos. Assim podemos dizer que a ilustração, bem como o poema, dialogam com a imaginação da matéria e a dimensão onírica da água.

Quanto à ilustração do poema "V", esta caminha na mesma perspectiva de ludicidade, sonho e imaginação do poema anterior.

Figura 4 - Ilustração de Ana Raquel para o poema "V". 


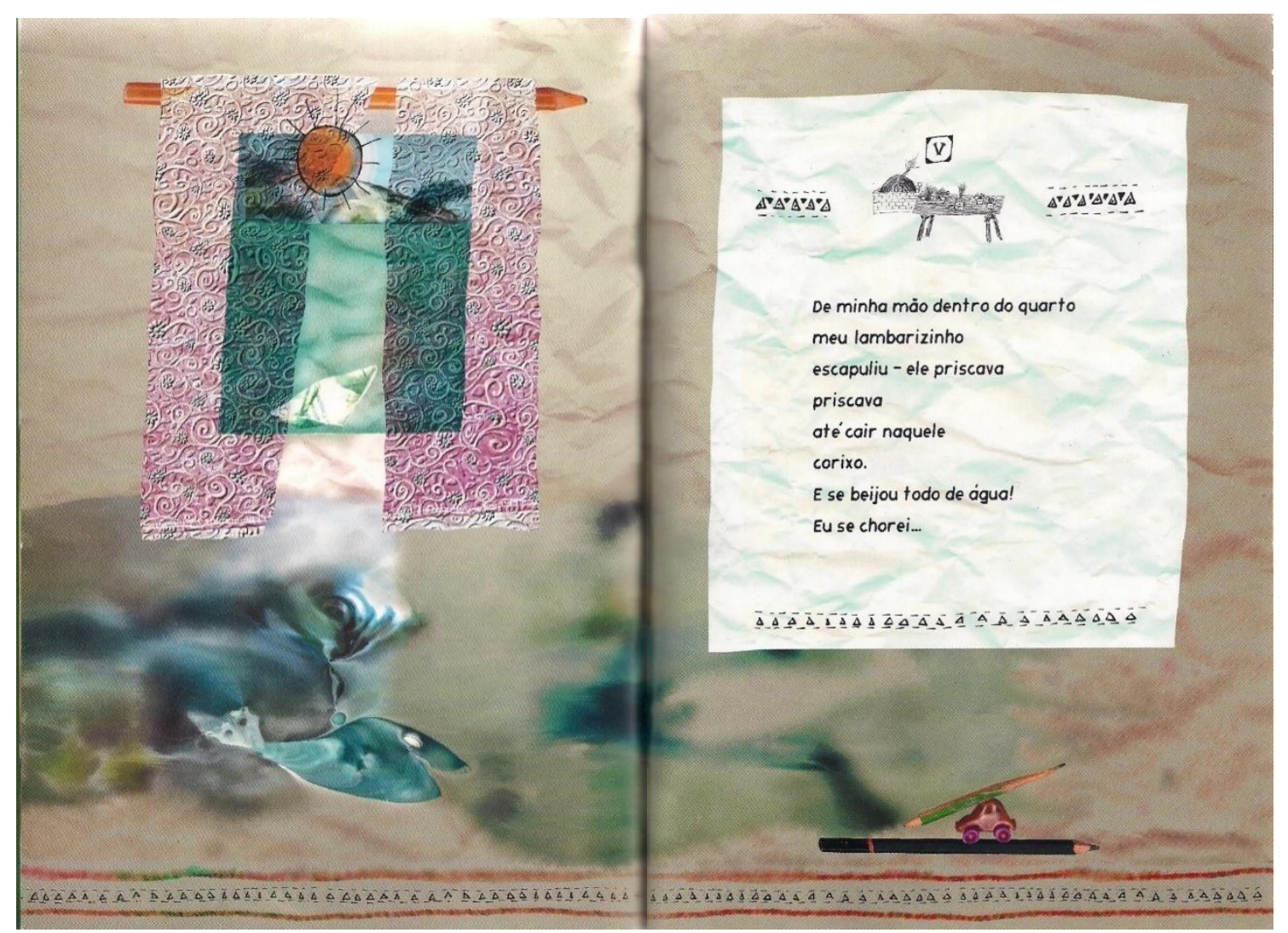

Fonte: BARROS, 2001, n.p.

As duas linhas paralelas inferiores que perpassam a ilustração das páginas estão coloridas com tonalidades advindas do vermelho e do azul; notam-se essas cores e suas variações predominantes em toda a ilustração. Do primeiro temos o laranja produzido pela mistura com o amarelo, e a cor rosa que é resultado da dessaturação ${ }^{3}$ com o branco.

Segundo Pedrosa, "na natureza, as cores tendem a mesclar-se com o azul do ar atmosférico, influindo nas mutações cromáticas” (2014, p.125). É o que se observa na paisagem vista pela janela. $\mathrm{O}$ azul mistura-se ao verde, criando outras tonalidades. Nessas áreas de transição, o ritmo da cor torna-se mais veloz e onde há contraste de cores - no caso do azul esverdeado e rosa, o movimento visual fica mais lento (OSTROWER, 1996).

Percebe-se um pouco de volume no barquinho de papel e nas ondas da água, onde podemos localizar as diagonais, que "introduzem a dimensão da profundidade" (OSTROWER, 1996, p. 81. Grifo da autora). Por outro lado, na dimensão da janela, em que geralmente o elemento volume está presente, visualizamos uma área bidimensional.

Fica explícito o caráter lúdico do jogo visual, feito pela ilustradora ao se utilizar do lápis, deslocando-o para outro contexto: com o de cor preta e o laranjado, desenha-se e colorese o sol que não está atrás, mas à frente da parede, invertendo a lógica. Os lápis são

${ }^{3}$ Refere-se ao clareamento da cor pura (saturada) por tons cinzas ou branco. 
apresentados em tamanho maior que o real, sendo que o laranja exerce a função de varão para a cortina, e o preto é a trilha por onde anda o carrinho; este ainda carrega um outro lápis que, pelas características pictóricas, parece estar no fim da vida útil.

[...] a imagem tem função lúdica quando orientada para o jogo (incluindo-se o humor como modalidade de jogo), seja em relação ao emissor, ao referente, à forma da mensagem visual ou mesmo em relação ao destinatário. Assim, a imagem enfatiza o jogo em relação ao referente quando apresenta situações cômicas; enfatiza o jogo em relação à forma da mensagem quando utiliza um estilo caricato; e, em relação ao destinatário, quando incentiva a participação do leitor, por exemplo, configurando-se como jogo. (CAMARGO, 2003, p.277-278. Grifos do autor).

Neste caso, as imagens e o poema relacionam-se com o "destinatário", que, provavelmente - mas não necessariamente -, é o infantojuvenil. Lápis de cor, barco de papel, carrinho e janela um tanto fantástica são objetos que configuram o espaço como sendo quarto de criança.

Na ilustração, na água, logo abaixo da cortina, o olho do "lambarizinho" irradia luz enquanto é observado pelo olho de água.

Vejamos o poema.

$\mathrm{V}$

De minha mão dentro do quarto

meu lambarizinho

escapuliu - ele priscava

priscava

até cair naquele

corixo.

E se beijou todo de água!

Eu se chorei...

(BARROS, 2001, n.p.)

Chama atenção no primeiro verso o recurso da inversão, enfatizando a mão da criança que segurava o peixinho fujão. Contudo, a fala de João só obedece ao seu pensamento infantil e leva o leitor a participar do devaneio. Pelo pensamento lógico, poderíamos dizer que o pequeno peixe fugiu da mão do menino e caiu num aquário, mas a imaginação da matéria (BACHELARD, 2013) permite sonharmos com um volume maior de água.

O pequeno redemoinho da ilustração está personificado e mostra um olho, que parece acariciar o "lambarizinho", dialogando com o verso 7, e mostrando a função maternal da água. "Dos quatro elementos, somente a água pode embalar. É ela o elemento embalador. Este é mais um traço de seu caráter feminino: ela embala como uma mãe" (BACHELARD, 
2013, p.136. Grifos do autor). Nota-se o movimento visual envolvendo água/olho/peixe pela posição de tons claros e escuros cuidadosamente intercalados. "O claro, referido visualmente ao escuro e avançando, se irradia e se expande; referido visualmente ao claro, o escuro recua e se contrai" (OSTROWER, 1996, p.223). Nessa perspectiva, o olho da água - onde se observa uma considerável área clara - se destaca e outros elementos parecem girar em torno dele. Bachelard vai dizer que a água é um grande olho que emite luz e cria o cosmo. A água é mais luminosa que o sol, uma vez que é ela a protagonista dessa natureza cósmica.

Mas será o lago ou será o olho que contempla melhor? [...] O lago é um grande olho tranquilo. $\mathrm{O}$ lago recebe toda a luz e com ela faz um mundo. [...] Ao pé do lago, compreende-se a velha teoria fisiológica da visão ativa. Para a visão ativa, parece que o olho projeta luz, que ele próprio ilumina suas imagens ( BACHELARD, 2013, p.30-31. Grifo do autor).

A autossuficiência da água se constata à medida que a enxergamos, seja no quarto pois o peixe não sobreviveria sem ela, - no corixo ou na lágrima do João: "Eu se chorei...".

Cabe ressaltar ainda o paralelismo do pronome "se", no penúltimo e último verso: "E se beijou todo de água! / Eu se chorei..." Quem se beija "todo de água” é o peixinho, enquanto o João se banha em lágrimas, pelo ocorrido, já que assim perdeu seu "lambarizinho" para o “corixo". Independente da posição que cada personagem ocupa em relação ao líquido, é possível constatar que o paralelismo expande o efeito umidificado pelo qual ambos estão envolvidos.

\section{Considerações finais}

Embora as ilustrações sejam uma releitura do texto poético, entendemos que, aliadas aos versos, colaboram para as ideias de ternura e vínculo de unidade entre o menino e o rio, sendo um dos pontos que validam o projeto de reedição da obra. É interessante ressaltar que há várias técnicas usadas nas ilustrações que ampliam os sentidos das imagens, por exemplo, nas diferentes representações do barco, em desenho, fotografia da dobradura e pintura.

Por outro lado, na perspectiva da teoria bachelardiana que percebe a água enquanto matéria para a imaginação dos sonhos, visualizamo-la pela visão especular observada no plano gráfico da capa do livro. Nesse sentido, o espelho da água pode refletir inúmeros outros planos: pode ser a metáfora do olho que enxerga a natureza até ser vista por ela numa dimensão onírica da imaginação da matéria (poema V); o cenário para que os animais 
aquáticos participem de seu espetáculo (poema I e II), para que dentro dela gozem do seu devaneio.

Ilustrações com características do Surrealismo remetem à ilogicidade lexical, sintática dos poemas. Concordando com Ramos (2005, p.171), quando diz que o poeta "prefere [...] entortar a sintaxe e criar neologismos", podemos concluir que a singularidade do verbo associada ao pictórico consegue unir o real e o surreal das águas, provocando o estranhamento e o encanto do leitor.

\section{Referências}

BACHELARD, Gaston. A água e os sonhos: ensaio sobre a imaginação da matéria. Trad. Antônio de Pádua Danesi. 2. ed. São Paulo: Editora WMF Martins Fontes, 2013.

BARROS, Manoel de. In: SÓ DEZ por cento é mentira. Documentário. Direção: Pedro Cezar Duarte Guimarães. Produção: Artezanato Eletrônico. Co-produção: VIT Produções, 2008. Intérpretes: Manoel de Barros, Bianca Ramoneda, Joel Pizzini, Jaime Lebovitcht, Paulo Giannini, Abílio de Barros, Palmiro, Viviane Mosé, Danilinho, Fausto Wolff, Salim, Martha Barros, João de Barros, Stella Barros, Elisa Lucinda, Adriana Falcão. Longa-metragem (01h $21 \mathrm{~m}$.), son., color.,Disponível em: <http://www.youtube.com/watch?v=XCMczEBuII4 > Acesso: 28 jul. 2015.

. Poeminhas pescados numa fala de João. Imagens de Ana Raquel. 2. ed. Rio de janeiro: Record, 2001.

BASTOS, Luciete. Fazendeiro de poesias: uma leitura do livro ensaios fotográficos de Manoel de Barros. Letras de hoje, Porto Alegre, n. 2, vol. 39, jun. 2004. Disponível em: $<$ http://revistaseletronicas.pucrs.br/ojs/index.php/fale/article/view/13825/9155> Acesso em: 20 jun. 2015.

CAMARGO, Luís. Para que serve um livro com ilustrações? In: JACOBY, Sissa. (org.) A criança e a produção cultural: do brinquedo à literatura. Porto Alegre: Mercado Aberto, 2003.

GRÁCIA-RODRIGUES, Kelcilene; MORAES, Paulo Eduardo Benites de. Manoel de Barros entre tradição e renovação. LETRAS \& LETRAS, Uberlândia, n. 1, v. 31, jan./jun. 2015. Disponível em: <http://www.seer.ufu.br/index.php/letraseletras> Acesso em: 25 nov. 2016.

OSTROWER, Fayga.Universos da arte.11. ed. Rio de Janeiro: Campus, 1996.

PEDROSA, Israel. Da cor à cor inexistente. 10. ed. 3. reimpr. Rio de Janeiro: Senac Nacional, 2014.

RAMOS, Isaac Newton Almeida. A modernidade em Manoel de Barros e Alberto Caeiro. In: LEITE, Mário Cezar Silva. (org.). Mapas da mina: estudos de literatura em Mato Grosso. Cuiabá: Cathedral Publicações, 2005. 
RAQUEL, Ana. Explicação. In: BARROS, Manoel de. Poeminhas pescados numa fala de João. Imagens de Ana Raquel. 2. ed. Rio de janeiro: Record, 2001. 